\title{
Effect of long-term sponsorship of the Škoda Auto brand and international sport events on congruence of brand personality
}

\author{
Eva Čáslavová*, Andrej Višněvský
}

Department of Sport Management, Faculty of Physical Education and Sport, Charles University, Prague, Czech Republic

* Corresponding author: caslavova@ftvs.cuni.cz

\begin{abstract}
The research examines the influence of long-term sponsorship on congruence (perceived consensus) of personal characteristics between Škoda Auto and sponsored international sport events such as the Ice Hockey World Championship and Tour de France. To identify personalities of these three subjects' brands we used a standardised personality scale created by Geuens, Weijters and De Wulf in 2009, which was developed to measure brands of various product categories. To measure personality congruence we used the absolute differentiation method (Gwinner \& Eaton, 1999). Data were collected via online questionnaires in January and February 2015. The research file formed a quote sample of 250 Prague respondents. Personal characteristics were evaluated via a seven-point Likert's scale expressing a degree of agreement or disagreement. The results show that the Škoda Auto brand is mostly characterized by the Responsibility dimension, whereas the brands of international sport events such as the Ice Hockey World Championship and Tour de France are mostly characterized by the Activity dimension. Respondents marked Aggresivity and Emotionality as undescriptive dimensions of Škoda Auto, and Simplicity and Emotionality as undescriptive dimensions of international sport events.
\end{abstract}

\section{KEYWORDS}

sponsorship; brand personality transfer; sport marketing; brand strategy; lce Hockey World Championship; Tour de France

DOI

$10.14712 / 23366052.2019 .4$

(c) 2019 The Authors. This is an open-access article distributed under the terms of the Creative Commons Attribution License (http://creativecommons.org/licenses/by/4.0), which permits unrestricted use, distribution, and reproduction in any medium, provided the original author and source are credited. 


\section{INTRODUCTION}

Sponsorship, aside from traditional advertising, is no longer an alternative way of brand promotion, but has become a full-fledged form of marketing communication. Despite the global economic crisis in 2008, total worldwide expenditures on sponsorship continue to grow. Global spending on sponsorship grew by $30.7 \%$ between 2009 and 2015, according to IEG (2016). In 2015, global spending on sponsorship totalled USD 57.5 billion, of which sport sponsorship accounted for 70\% (IEG, 2015). On the other hand, with the ever-growing popularity of sponsorship it is getting more and more difficult to provide brands with the required market differentiation through sponsorship. It has become commonplace to see business and sport managers endeavouring to come up with unique sponsorship projects and replaced the traditional display of logos at sports grounds. For example, sponsor's brand products are interlinked with a sport event, but are these projects more efficient considering the sponsorship objectives? Can such interlinking of a brand with a sport event be strong enough to trigger a positive image transfer from the sport event to the brand? Research of sponsorship suggests that there are numerous factors that may affect the efficiency of image transfer in sponsorship. Woisetschläger, Haselhoff and Backhaus (2013), for example, found that the efficiency of sponsorship might be impaired by the fans' aversion to changes in names of sponsors, mainly in clubs strongly influenced by tradition. Still, Neijens, Smit and Moorman (2009) pointed out a positive effect of image transfer in sponsorship even three months after the end of a sport event. Chanavat, Martinent and Ferrand (2010) identified lower efficiency of such transfer in a brand involved in sponsorship of multiple sports entities simultaneously. The studies referred to above indicate that although global spending on sponsorship continues to grow, sponsorship is a complex topic deserving deeper investigation.

Image congruence (or perceived congruity) between a sports entity brand and a sponsor's brand (Lee \& Cho, 2009) is one of the image transfer measures. Congruence means a degree of both direct and indirect relevance between the sponsor and the event (McDonald, 1991; Musante \& Milne, 1999). When investigated, congruence can be measured as a whole or as congruence of selected image components that are classified by Keller (2008) as brand attributes and benefits, typical user, brand heritage, and brand personality. In recent years, the attention has moved toward the brand personality concept. Schade, Piehler and Burmann (2014) emphasize the importance of the brand personality in its function of behavioural relevance. Thus, the brand personality becomes a key element affecting the overall image of the brand. These are the reasons why the congruence of personalities of the international sport events brands and their sponsor's brand are dealt with in this paper.

When it comes to huge international sport events like the Ice Hockey World Championship or Tour de France, companies tend to focus on long-term strategic sponsorship agreements that are regularly renewed based on assessment of previous cooperation. It is quite common to extend cooperation unless the sponsor or the sponsee wish to significantly change their image and marketing strategy. Suppose that the longer the sponsorship, the better the association of the brand with the sport event in the customer's mind and sponsorship, thus, becomes more efficient. The purpose of this paper is to find out if long-term sponsorship positively contributes to a higher degree 
of brand personality congruence between an international sport event and its sponsor. This was exactly why we chose Škoda Auto, a brand holding the Guinness record in the duration of sponsorship provided to the Ice Hockey World Championship. Škoda Auto has been a sponsor of this international sport event since 1992. For comparison, another major sport event that has been sponsored by Škoda Auto since 2004, the Tour de France, was selected.

\section{METHODS}

The first step to achieve the goal of the research is the selection of a suitable brand personality scale. There are universal scales to measure the personality of various product categories (Aaker, 1997; Geuens, Weijters, \& De Wulf, 2009), and specific scales designed for a specific product category (Lee \& Cho, 2012; Sung, Choi, Ahn, \& Song, 2015). Personality characteristics of universally applicable scales are set to allow identification of brand personalities on a general level while making it possible to mutually compare more brands of various product categories. On the other hand, specific scales comprise specific personality characteristics that are typical for one product category only. The higher the universality of a scale, or its ability to apply the measurement on a larger number of product categories, the lower the quality of a unique personality description in one product category. For this particular reason marketing experts have recently recommended applying specific scales designed in the context of brand product uniqueness if brands of one product category are investigated (Ross, 2008). The goal set for this research is to compare brands of various product categories (automotive industry and international sport events) and, therefore, our attention was focused on the group of universal scales.

In 1997, J. F. Aaker designed the first standardized universal scale for brand personality measurement within various product categories. Aaker proceeded from her definition of brand personality: "The set of human characteristics associated with brand" (Aaker, 1997, p. 347). The scale contains 42 personality traits and has been applied in research (Lee \& Cho, 2009; Grohmann, Giese, \& Parkman, 2013). Enormous attention given to this scale stirred a discussion among experts about its pros and cons. The main criticism was directed against the general definition of brand personality, high number of personality characteristics and insufficient applicability of the scale in different cultural environments (Geuens et al., 2009). Azoulay and Kapferer (2003, p. 151) suggested a new definition of brand personality and they describe it as "the set of human personality traits that are both applicable to and relevant for brands." Even though they use psychological science to describe human personality, this definition does not allow for a scale with personal traits that cannot be applied in marketing for a brand entity. Based on the definition by Azoulay and Kapferer, a new standardized universal scale of brand personality was created by Belgian authors Geuens et al. (2009). Tested in the U.S.A. and nine European countries (Geuens et al., 2009), the scale is limited to as few as 12 personality characteristics. No other recognized universal scale has been designed for brand personality since 2010. Instead, specific scales to measure specific product categories are being developed, e.g. nation brand personality scale (Kim, Shim, \& Dinnie, 2013), luxury brand personality scale (Sung et al., 2015), and for sports there are sport club personality scale (Schade, Piehler, \& Burmann, 
2014) and sport event personality scale (Lee \& Cho, 2012). Analysis of the available standardized universal scales implied that the scale by Geuens et al. (2009) in Figure 1 is the most suitable scale for our research since it was created in the European cultural environment, it contains a low number of personality traits and, moreover, it is based on the strictly defined brand personality according Azoulay and Kapferer (2003).

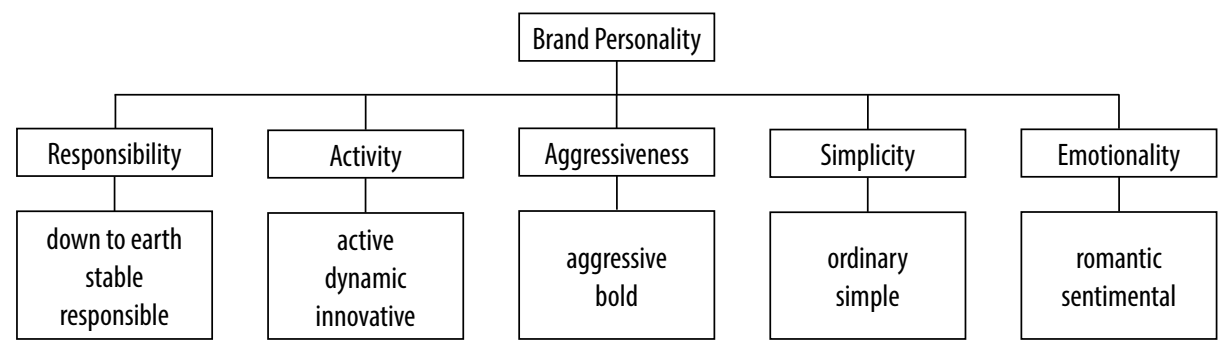

Figure 1 Brand personality according Geuens, Weijters, and De Wulf (2009)

Our research is a follow-up to a number of previous brand research projects focused on sports (Čáslavová \& Petráčková, 2011; Čáslavová \& Višněvský, 2016) that have been performed at the Department of Sport Management, Faculty of Physical Education and Sports, Charles University, since $2000 .^{6}$

The basic research sample - relevant target group of people in the population was determined in view of the research objectives and the type of the investigated brands. Some brand personality research projects performed abroad resorted to homogeneous cohorts of students (Ambroise, Ferrandi, Merunka, \& Valette-Florence, 2005; Lee \& Cho, 2012), while some other surveys used panels to collect representative data (Aaker, 1997; Geuens et al., 2009; Schade et al., 2014). International sport events appeal to a wide range of persons in the society and homogeneous groups of students, therefore, are not relevant for our research. We decided to measure the brand personality on the Prague population. Being aware of how difficult it would be to perform a random selection from all people living in Prague, we opted for quota sampling of respondents. Two basic demographic quotas, gender and age, were applied. It was decided not to include any other demographic variables as it would have been impossible for us to control them in research. Median, a survey agency specializing in pre-election

Table 1 Quotas of the capital city of Prague

\begin{tabular}{l|l|l}
\hline Gender & Male & $48 \%$ \\
& Female & $52 \%$ \\
\hline Age & $18-29$ years & $18 \%$ \\
& $30-44$ years & $32 \%$ \\
& $45-59$ years & $21 \%$ \\
& 60 years and older & $29 \%$ \\
\hline
\end{tabular}

6 The study is part of the Progress Q19 research programme. 
public opinion surveys in the Czech Republic, provided statistics regarding the current structure of Prague inhabitants. Making use of Median's information on the structure of Prague's inhabitants from September to October 2014, we obtained a sample of 250 respondents representing Prague population by gender and age.

The intention was to collect data during a period when neither of the investigated international sport event takes place in order to avoid any influence on the perception of brand personality from publicity. It was decided to collect data in January and February 2015. We compiled a questionnaire in both printed and electronic versions. The printed version was used mainly by respondents of older age groups. Respondents were asked to evaluate personality traits on a Likert scale ranging from 1 to 7 . Each value corresponded to a degree of agreement with the listed traits and to what extent the traits describe or fail to describe the brand. Value 1 equals absolutely not describing while value 7 equals perfectly describing.

The data analysis consists of two parts. In the first part, the personality of three brands, Škoda Auto, Ice Hockey World Championship, and Tour de France, was identified through the mean, standard deviation, and mode. Higher values of mean dimensions and traits indicated a higher degree of agreement with an item characterizing the brand. The standard deviation quantified the amount of dispersion of respondents' responses on the Likert scale. Thus, a lower value of the standard deviation suggested a rather unified opinion of respondents on the given dimension or trait. Representing the mean of the measured standard deviations lying in the interval $(1.32 ; 2.07)$, the boundary value of standard deviation was set to 1.7. The mode indicated the most frequently occurring responses on the Likert scale regarding the traits. In the second part, congruence of brand personality between Škoda Auto and the sport events was measured. Absolute difference statistics by Gwinner and Eaton (1999) was applied to quantify congruence. For a Likert scale, it is calculated as an absolute difference in values on a scale between two measured brands and, in cases of a seven-point scale, the resulting value falls within the interval $(0 ; 6)$. If the difference in personality perception between two brands is small, the absolute difference will be close to 0 . Only if there is absolute congruence of a respondent's answers between two brands, would the number equal 0 . The smaller the absolute difference between two brands, the more congruent their personality.

\section{RESULTS}

\section{Identification of the Škoda Auto brand personality}

The respondents rated Škoda Auto as a responsible, active, and simple brand. Aggressiveness and Emotionality were rejected as not matching dimensions.

Huge differences in the rating of traits included in the Responsibility dimension $(\mathrm{N}=4.99 ; \mathrm{SD}=1.51)$ were observed. Stable and Responsible are the two best describing characteristics of the Škoda Auto brand. These items earned the most unambiguous expression of the respondents' opinion in the whole questionnaire. Stable and Responsible were considered to be describing (values 5 to 7 on the Likert scale) by $81 \%$ and $73 \%$ of respondents, respectively. This manifested in high values of the mean and, at the same time, low values of the standard deviation as shown in Table 2. Down to Earth was considered as not describing. 
Active and Dynamic within the Activity dimension $(\mathrm{N}=4.84$; $\mathrm{SD}=1.45)$ were marked as the best matching traits. Active and Dynamic were considered to be describing by $66 \%$ and $62 \%$ of respondents, respectively. Again, Table 2 shows a positive perception of both these items on the values of the mean and standard deviation. The trait Innovative was rated within the positive range of values 5 to 7 by $52 \%$ of respondents. Nevertheless, the neutral value of 4 (partly describing) was the most frequent response to the question about Innovative. This implies that Škoda Auto is not unambiguously perceived as being innovative.

Simplicity $(\mathrm{N}=4.54 ; \mathrm{SD}=1.62)$ is the last dimension of the Škoda Auto brand that is positively rated by respondents as describing. First and foremost, Simple was marked as describing by $57 \%$ of respondents, but only $9 \%$ of respondents assigned this trait with 7, the highest value on the Likert scale (perfectly describing). Table 2 shows a low standard value for this item, which indicates alignment of respondents' opinions. Ordinary was also marked as describing by more than a half of respondents (51\%). In this case, the opinions are diverse due to the high standard deviation.

The trait Aggressive within the Aggressiveness dimension $(\mathrm{N}=3.40 ; \mathrm{SD}=1.64)$ achieved a low mean and a relatively higher standard deviation as shown in Table 2. In total, $62 \%$ of respondents marked this characteristic as not describing (values 1 to 3 on the Likert scale). Almost not describing (2) was the most frequent response. Marked as not describing by $48 \%$ of respondents, a slightly less negative response was observed for the trait Bold. The Škoda Auto brand is perceived as neither aggressive nor bold.

Respondents expressed the highest degree of disagreement when asked about the Emotionality dimension $(\mathrm{N}=2.92 ; \mathrm{SD}=1.71)$. The high value of standard deviation found in both characteristics indicates a lack of unity of their opinions. Romantic and Sentimental were marked as not describing by $71 \%$ and $61 \%$ of respondents, respectively. The lowest value 1 on the Likert scale (absolutely not describing) was the most frequent response for both these traits.

\section{Identification of the Ice Hockey World Championship brand personality}

The Ice Hockey World Championship was rated as an active, partly responsible and aggressive brand. Compared to the Škoda Auto brand, the mean values of the dimensions are lower, while the standard deviations of the dimensions are higher and this indicates less aligned opinions regarding the brand personality.

Activity $(\mathrm{N}=4.86 ; \mathrm{SD}=1.62)$ is the highest rated dimension of this brand. The mean of the dimension is significantly affected by the low mean of the trait Innovative, which strongly differs from the remaining characteristics: Active and Dynamic. These traits were marked as describing (values 5 to 7 ) by $70 \%$ and $67 \%$ of respondents, respectively. The positive rating is proven by the highest values of the mean shown in Table 2 . In addition, more than $25 \%$ of respondents chose the highest value 7 (perfectly describing) for both these traits. The Ice Hockey World Championship is, therefore, strongly perceived as an active and dynamic brand.

Responsibility $(\mathrm{N}=4.22$; $\mathrm{SD}=1.65)$ is considered to be the second best matching dimension of the Ice Hockey World Championship brand personality. Stable is the highest rated characteristic within this dimension. In total, $51 \%$ of respondents marked this item on the Likert scale as describing. As shown in Table 2, opinions of 
respondents are not aligned due to the high standard deviation. The Down to Earth characteristic received the lowest mean within the dimension. A big number of respondents (39\%) marked this trait as not describing. It can be concluded that the Ice Hockey World Championship is considered to be a stable and responsible brand.

Aggressiveness $(\mathrm{N}=4.10 ; \mathrm{SD}=1.76)$ was rated as a partly matching dimension. Compared to the results achieved by the other investigated brands, the Ice Hockey World Championship is perceived as the most aggressive brand. The trait Aggressive is considered to be describing by $41 \%$ of respondents and the same percentage of respondents perceives the trait as not describing. This is the reason why this trait also received a high standard deviation in Table 2 . The trait Bold achieved a similar rating, $45 \%$ of respondents marked this trait as describing and this revealed itself in the higher mean. Still, the inconsistency of responses remains high due to higher standard deviation.

Simplicity $(\mathrm{N}=3.72$; $\mathrm{SD}=1.64)$ was marked as a dimension that does not match the Ice Hockey World Championship brand personality. $49 \%$ of respondents perceive Ordinary as not describing. Table 2 shows that the mean was below the neutral value of 4 . The lower standard deviation indicates a relatively high alignment of opinions. The trait Simple ended up with a less clear answer. Although respondents continue to perceive it as a trait that does not match the Ice Hockey World Championship, their responses are more dispersed across the Likert scale. Still, $44 \%$ of respondents lean towards the option that this trait does not describe the brand.

As for Emotionality $(\mathrm{N}=3.00 ; \mathrm{SD}=1.94)$, the trait Romantic achieved the lowest mean of all traits measured and summarized in Table 2 . In total, $71 \%$ of respondents marked this trait as not describing. On the other hand, the second trait included in this dimension, Sentimental, achieved the highest standard deviation in the whole survey, which shows evidence of significantly different individual opinions of respondents. The Mode statistics in Table 2 makes it obvious that these two characteristics mostly received value 1 on the Likert scale (absolutely not describing). This rating was selected by $36 \%$ of respondents for Romantic and by $29 \%$ of respondents for Sentimental.

\section{Identification of the Tour de France brand personality}

Tour de France is depicted as an active and partly responsible brand. The means and standard deviations of the dimensions are similar to those achieved by the Ice Hockey World Championship brand. However, there are differences in the characteristics assigned to the Tour de France brand.

Activity $(\mathrm{N}=4.87$; $\mathrm{SD}=1.66)$ was marked as the best matching dimension. The scores of traits within this dimension vary greatly. According to the mean values listed in Table 2, 69\% of respondents agreed with Active as the best describing trait of Tour de France. The high rating of this trait is emphasized by the fact that the highest possible value on the Likert scale became the most frequently chosen response. The percentage of positive responses indicates that respondents marked Dynamic as the best matching item. As many as $71 \%$ of respondents chose this trait as describing and, moreover, responses with the highest value on the Likert scale occurred most often. It should also be stressed that, while expressing how consistent or dispersed the responses are, the standard deviation achieved higher values compared to the previously analysed brands. Only $47 \%$ of respondents marked Innovative as a matching trait. The 
rating of this trait, thus, differs significantly from the remaining items included in this dimension.

Responsibility $(\mathrm{N}=4.16 ; \mathrm{SD}=1.69)$ was marked as a partly describing dimension. The inconsistency of results achieved in each of the characteristics within this dimension is also quite obvious. Stable was marked as describing by $56 \%$ of respondents. Table 2 shows a significantly high value of the standard deviation, which shows evidence of a lack of alignment of opinions. Down to Earth received an opposite rating, $46 \%$ of respondents marked this item as not describing. Again, the responses for this trait were rather dispersed. The trait Responsible was rated as partly describing. It was marked as describing by $39 \%$ of respondents and as partly describing by $29 \%$ of respondents. The standard deviation shown in Table 2 was low and this means that respondents shared a common opinion on this trait.

Based on the statistical result, the Aggressiveness dimension $(\mathrm{N}=4.04 ; \mathrm{SD}=1.69)$ can be considered as partly describing. If we look at the traits in more detail, we notice that $46 \%$ of respondents marked Aggressive as not describing, while $47 \%$ respondents perceived Bold as describing. If anything, this dimension contains two characteristics that received different rating from respondents.

Simplicity $(\mathrm{N}=3.74 ; \mathrm{SD}=1.62)$ was marked as not describing. Compared to the standard deviations of the other dimensions shown in Table 2, the value of this dimension of the Tour de France brand personality scored the lowest. The statistics of the traits within this dimension do not differ significantly. The trait Ordinary is considered to be less matching. It was marked as not describing by $45 \%$ of respondents. Simple scored closer to the neutral value of 4 (partly describing) as only $38 \%$ and $29 \%$ of respondents marked it as not describing and partly describing, respectively.

Having the Tour de France brand in mind, the Emotionality dimension $(\mathrm{N}=3.23$; $\mathrm{SD}=1.80$ ) was rated as not describing by the respondents. As with the Ice Hockey World Championship, the opinions are rather dispersed, which is demonstrated by the high standard deviations in the traits shown in Table 2. Romantic was marked as not describing by $58 \%$ of respondents. One quarter of respondents rated this trait as absolutely not describing (the lowest value on the Likert scale). A slightly less negative opinion was recorded for Sentimental, $51 \%$ marked this trait as not describing.

Table 2 Identification of the Škoda Auto, Ice Hockey World Championship, Tour de France brand personality

\begin{tabular}{lcclccc}
\hline \multicolumn{7}{c}{ Škoda Auto } \\
\hline Dimension & Mean & SD & Characteristics & Mean & SD & Mode \\
\hline Responsibility & 4.99 & 1.51 & down to earth & 4.44 & 1.61 & 5 \\
& & & stable & 5.50 & 1.40 & 6 \\
& & & responsible & 5.05 & 1.32 & 5 \\
Activity & \multirow{2}{*}{1.45} & active & 4.98 & 1.34 & 5 \\
& & & dynamic & 4.89 & 1.49 & 5 \\
& & & innovative & 4.66 & 1.50 & 4 \\
Aggressiveness & \multirow{2}{*}{3.40} & \multirow{2}{*}{1.64} & aggressive & 3.08 & 1.58 & 2 \\
& & & bold & 3.72 & 1.63 & 3
\end{tabular}




\begin{tabular}{|c|c|c|c|c|c|c|}
\hline \multirow[t]{2}{*}{ Simplicity } & 4.54 & 1.62 & ordinary & 4.46 & 1.71 & 4 \\
\hline & & & simple & 4.62 & 1.51 & 5 \\
\hline \multirow[t]{2}{*}{ Emotionality } & 2.92 & 1.71 & romantic & 2.73 & 1.63 & 1 \\
\hline & & & sentimental & 3.11 & 1.77 & 1 \\
\hline \multicolumn{7}{|c|}{ Ice Hockey World Championship } \\
\hline \multirow[t]{3}{*}{ Responsibility } & 4.22 & 1.65 & down to earth & 3.86 & 1.66 & 4 \\
\hline & & & stable & 4.47 & 1.69 & 6 \\
\hline & & & responsible & 4.32 & 1.53 & 5 \\
\hline \multirow[t]{3}{*}{ Activity } & 4.86 & 1.62 & active & 5.15 & 1.52 & 5 \\
\hline & & & dynamic & 5.12 & 1.61 & 7 \\
\hline & & & innovative & 4.30 & 1.59 & 4 \\
\hline \multirow[t]{2}{*}{ Aggressiveness } & 4.10 & 1.76 & aggressive & 4.02 & 1.75 & 5 \\
\hline & & & bold & 4.19 & 1.76 & 4 \\
\hline \multirow[t]{2}{*}{ Simplicity } & 3.72 & 1.64 & ordinary & 3.59 & 1.58 & 4 \\
\hline & & & simple & 3.85 & 1.68 & 4 \\
\hline \multirow[t]{2}{*}{ Emotionality } & 3.00 & 1.94 & romantic & 2.63 & 1.72 & 1 \\
\hline & & & sentimental & 3.37 & 2.07 & 1 \\
\hline \multicolumn{7}{|c|}{ Tour de France } \\
\hline \multirow[t]{3}{*}{ Responsibility } & 4.16 & 1.69 & down to earth & 3.76 & 1.70 & 4 \\
\hline & & & stable & 4.61 & 1.73 & 6 \\
\hline & & & responsible & 4.12 & 1.51 & 4 \\
\hline \multirow[t]{3}{*}{ Activity } & 4.87 & 1.66 & active & 5.14 & 1.63 & 7 \\
\hline & & & dynamic & 5.12 & 1.68 & 7 \\
\hline & & & innovative & 4.36 & 1.55 & 4 \\
\hline \multirow[t]{2}{*}{ Aggressiveness } & 4.04 & 1.69 & aggressive & 3.71 & 1.62 & 3 \\
\hline & & & bold & 4.36 & 1.69 & 4 \\
\hline \multirow[t]{2}{*}{ Simplicity } & 3.74 & 1.62 & ordinary & 3.59 & 1.57 & 4 \\
\hline & & & simple & 3.89 & 1.65 & 4 \\
\hline \multirow[t]{2}{*}{ Emotionality } & 3.23 & 1.80 & romantic & 3.11 & 1.74 & 1 \\
\hline & & & sentimental & 3.36 & 1.85 & 1 \\
\hline
\end{tabular}

\section{Congruence of brand personality between Škoda Auto and international sport events}

To measure the congruence between the Škoda Auto brand and the international sport events, the first step was to identify their personalities. Now, we have to assess the extent to which the resulting personalities of the three brands cohere on the Likert scale. It is assumed that the duration of sponsorship between the Škoda Auto brand and the sponsored sport events can affect the personality congruence of their brands. The sponsorship of the Ice Hockey World Championship has lasted 24 years and the sponsorship of Tour de France dates back 12 years. 
The congruence in traits within the dimensions was measured with the help of absolute difference. Table 3 quantifies the arithmetic mean of the absolute difference values between the following pairs: Škoda Auto vs. Ice Hockey World Championship and Škoda Auto vs. Tour de France. The arithmetic mean of the absolute difference values provides information about the magnitude of the average difference in rating of each pair of brands. As shown in Table 3, it lay within the interval $(1.20 ; 1.88)$. Table 3 thus shows that Škoda Auto vs. Ice Hockey World Championship is the pair of brands that has a lower average of absolute difference in most traits. This pair is more congruent in the following characteristics: Down to Earth, Responsible, Active, Bold, Ordinary, Romantic, and Sentimental. The second pair of brands, Škoda Auto vs. Tour de France, shows higher congruence in the remaining traits: Stable, Dynamic, Innovative, Aggressive, and Simple.

The values of the mean absolute difference do not provide any information about whether the congruent trait is both matching and not matching for the analysed brands. This is the reason why it is essential to interpret the values of the mean absolute difference in the context of the identified brand personality and according to the mean trait values. First, we set the boundary values for the mean and for the mean absolute difference. The value of 4 was set for the mean, i.e. the neutral position on the Likert scale, and the value of 1.54 was set for the mean absolute difference, this denotes the middle point of the interval within which the mean absolute differences of traits occurred. Next, we generated a chart where the midpoint of the axis is at the boundary values of both the statistics, coordinates $(1.54 ; 4)$, and we had four quadrants. Quadrant I is the most interesting for us as the traits contained there are congruent and, at the same time, describe the personality of both the brands. Chart 1 shows the location of traits identified for the first pair of brands, Škoda Auto and Ice Hockey World Championship. Active, Responsible, and Down to Earth are considered to be both congruent and describing the personality traits. Chart 2 illustrates the second pair of brands, Škoda Auto and Tour de France, where only Active was found in the first quadrant. The trait Dynamic is at the very boundary of congruence.

By comparing Charts 1 and 2, it can be concluded that the Škoda Auto brand is more congruent with the international sport event brand of the Ice Hockey World Championship than with the Tour de France brand. Congruence between the Škoda Auto and Ice Hockey World Championship brands was identified in three traits that were, moreover, marked by the respondents as describing. Only one trait marked by the respondents as describing showed congruence between the Škoda Auto and Tour de France brands. Our assumption that the duration of sponsorship positively affects the personality congruence of international sport events and sponsor's brands has been confirmed.

\section{DISCUSSION}

\section{Identification of brand personality}

Identification of the brand personality with the help of the mean value and standard deviation on the Likert scale makes it possible to recognize personality traits and determine to what extent a certain trait matches the brand (mean) and what is the prevailing opinion (standard deviation). For a brand manager, therefore, it would be ideal 
if, for the desired personality traits, the mean is as high as possible and the standard deviation remains as low as possible. This would represent a strong and unified opinion expressed by respondents. The identification of personalities of the Škoda Auto, Ice Hockey World Championship, and Tour de France brands indicated that the Škoda Auto brand received the best values of mean and standard deviation. The international sport event brands, on the other hand, achieved less distinctive results. It can be assumed that this outcome is partly impacted by the product category of the brands. Škoda Auto has a clearly defined tangible product, while the Ice Hockey World Championship and Tour de France render absolutely unique and comprehensive sport products.

Table 3 Mean absolute difference of responses on the seven-point Likert scale

\begin{tabular}{lcc}
\hline Characteristics & $\begin{array}{c}\text { Škoda Auto vs. Ice Hockey World } \\
\text { Championship }\end{array}$ & Škoda auto vs. Tour de France \\
\hline Down to earth & 1.52 & 1.57 \\
Stable & 1.76 & 1.70 \\
Responsible & 1.49 & 1.59 \\
Active & 1.39 & 1.48 \\
Dynamic & 1.71 & 1.54 \\
Innovative & 1.58 & 1.57 \\
Aggressive & 1.78 & 1.54 \\
Bold & 1.66 & 1.73 \\
Ordinary & 1.76 & 1.88 \\
Simple & 1.72 & 1.58 \\
Romantic & 1.20 & 1.48 \\
Sentimental & 1.59 & 1.71 \\
\hline
\end{tabular}

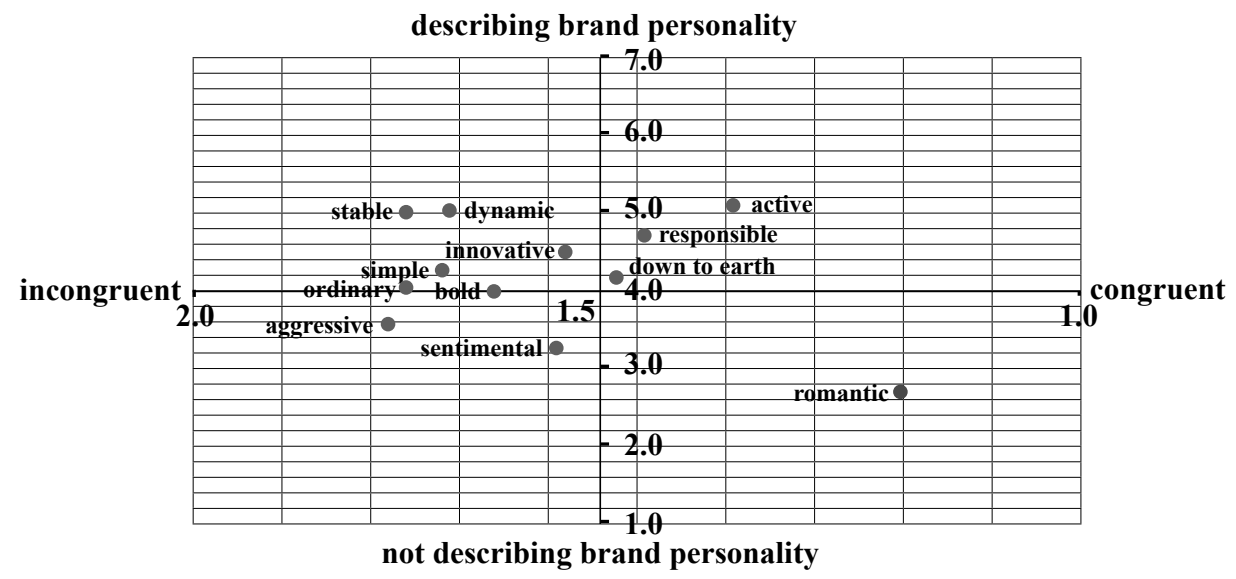

Chart 1 Congruence and mean values of the pair of brands: Škoda Auto and Ice Hockey World Championship 


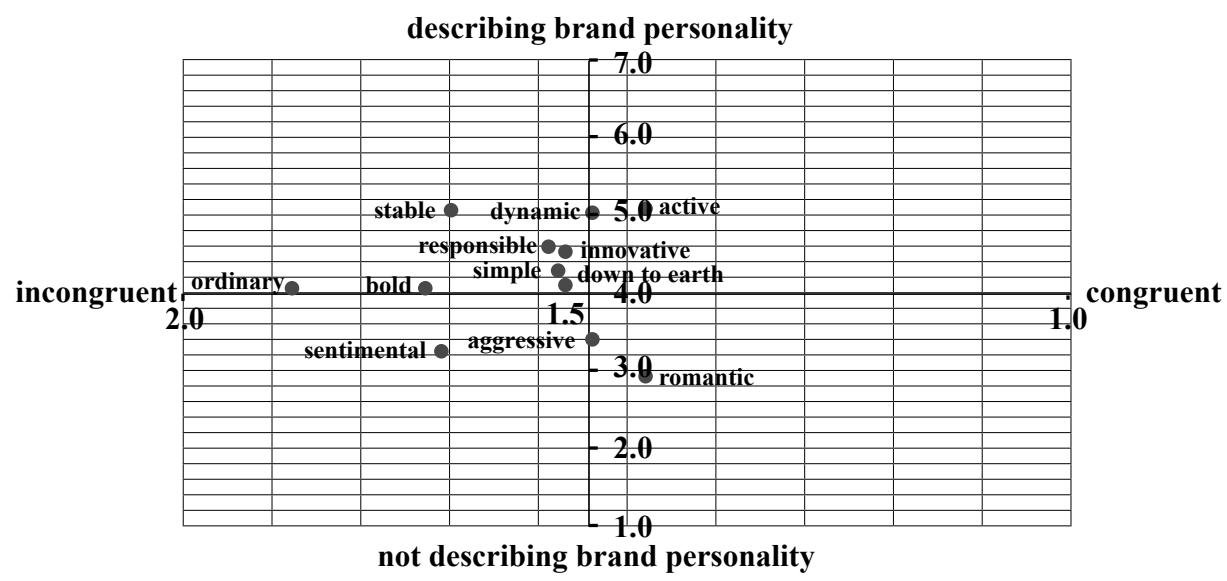

Chart 2 Congruence and mean values of the pair of brands: Škoda Auto and Tour de France

It is for this specific reason that applying a generally standardized brand personality scale to measure just brands in sports is deemed to be less appropriate, unless they are compared to brands of other product categories. A general brand personality scale is considered to be a well-suited measuring tool whenever brands of different product categories have to be compared, e.g. to measure the personality congruence as was the case in our study.

\section{Škoda Auto}

It was assumed that the Škoda Auto brand would be characterized by Responsibility and Simplicity. The assumption was based on our knowledge of the long-term publicity campaign where Škoda Auto highlights these traits. Putting the emphasis on responsibility is a widespread phenomenon in marketing communication of car brands, while emphasis on simplicity is a unique marketing communication of the Škoda Auto brand and "Simply Clever," the brand's motto, is a proof of that. The results confirmed the assumed ranking of these two dimensions. Additionally, the Activity dimension was also rated very positively. This result might indicate a transfer of the personality trait due to long-term sponsorship as this dimension also received high rating in the international sport events.

We consider Aggressiveness to be an undesirable dimension for the Škoda Auto brand. We are not certain if the management of Škoda Auto share our opinion and whether this characteristic is also considered undesirable as a certain degree of aggressiveness is a natural characteristic for ice hockey. Linking Škoda Auto with ice hockey could result in the transfer of this trait to the sponsor's brand. Moreover, the brand may be perceived as aggressive if an aggressive advertising campaign is waged against competitors. In the Czech Republic, this sort of campaign occurred between Škoda Auto and Hyundai.

Perceived by the respondents as a not describing dimension, the rating of Emotionality is deemed surprising. Emotions are extremely important for brands involved in sponsorship, and even more so if it is sponsorship of sports. In sponsorship, brands 
are presented to target groups of potential customers during their entertainment and leisure time. Emotions in sport are supposed to boost the public's attachment to the brand and enhance customer-brand relationships. For this reason, we were surprised to see that Škoda Auto is not perceived by the respondents as a brand that radiates emotions.

\section{Ice Hockey World Championship}

Variation over time, individual liking of the brand, and a narrower target group of customers are believed to be the factors making the rating of the Ice Hockey World Championship brand personality less distinctive. The variation over time results from the yearly rotation of countries hosting the Ice Hockey World Championship. Differences in the style and national traditions impact the image and perception of the international sport event's personality. Individual liking of the brand causes significant variation in the values on the Likert scale.

It was assumed that the Ice Hockey World Championship would predominantly be depicted by the Activity and Aggressiveness dimensions. As the Aggressiveness dimension was marked as only partly describing, our assumption was found to be only partly proved. Still, the mean of this dimension was higher in the Ice Hockey World Championship than in the remaining two brands. Naturally, ice hockey shows a higher degree of aggressiveness resulting from the game. Of course, it depends on the organizers and their ability to exploit this feature for the benefit of the brand.

Responsibility was rated as a matching dimension, which is considered to be an interesting outcome. For the whole duration of its existence, the Ice Hockey World Championship has never experienced any unfortunate scandals that could have impaired the brand's image. It was quite surprising for us to find that Emotionality was rated as not describing. It was expected that Emotionality would be one of the core characteristics of international sport event brands, but in fact this was the least matching dimension of the brand personality. The difficulty lies in the traits representing this dimension: Romantic and Sentimental. In our opinion, these two traits do not describe emotionality typical for the sports environment.

\section{Tour de France}

As for the identification of the brand personality of Tour de France, we were quite curious to see how the personality of this brand would be affected by the frequent doping scandals that, unfortunately, are rather typical for road cycling. It was slightly surprising for us to find that the results of the survey were quite similar to the brand identification of the Ice Hockey World Championship. Being strongly dependent on TV transmission, the way of presentation of this sport event can be another significant factor affecting the personality of Tour de France. Cycling is predominantly a TV sport. The image of Tour de France can be improved through television and, to achieve this, shots of historical places and high-mountain nature are widely used.

Slight differences as against the brand identification of the Ice Hockey World Championship were identified in Responsibility, Aggressiveness and Emotionality. Compared to the other measured brands, Tour de France is perceived as less responsible, which could be a consequence of the doping scandals. Yet, the difference is not too large. Similarly, this brand is perceived as less aggressive compared to the Ice Hockey 
World Championship. Although a more positive result was measured for Emotionality, the difference is very small and has no influence on the overall identification of the brand personalities.

\section{Congruence of brand personalities in sponsorship}

Each corporation deciding to enter into sponsorship pursues different marketing goals, based on which sponsorship planning is derived. In the Czech Republic, Škoda Auto belongs to the most successful Czech brands in the international market. Therefore, the marketing activities must have a global impact. Sponsorship of international sport events is an ideal opportunity to enhance the brand awareness abroad and build its global image. In our opinion, Škoda Auto adopted a strategically effective behaviour as its sponsorship of the Ice Hockey World Championship and Tour de France focuses on different regions and different target groups in the population. Involved in sponsorship of the Ice Hockey World Championship, Škoda Auto approaches the European market, particularly its Northern and Central European regions, and the Russian market. Sponsorship of Tour de France, on the other hand, puts the main emphasis on Southern European countries and the USA. Different duration of sponsorship with the international sport events was the decisive factor when selecting this brand for the survey. We were looking for a brand that has been involved in sponsorship of sport events for at least ten years to see the impact of the duration on the congruence of personality. The second condition was that there should be a sufficient difference between the duration of sponsorship of the first sport event and the sponsorship of the second sport event.

In case that the transfer (congruence) of the brand personality has been perfectly accomplished between the sport event and the sponsor, the values of absolute difference would be low in all twelve personality characteristics. In real sponsorship, however, only partial congruence is achieved in certain traits. To know which traits have shown congruence can be of key importance in achieving the transfer of image. It is desirable for both the sponsor and the international sport event that the traits be congruent in the high values of the mean. If the sponsor achieved congruence with the sport event in traits showing a low value of the mean (traits that do not match the brand), the transfer of image would not be efficient. The brands would then differ in what defines them. Conversely, the transfer of image would work well if a degree of congruence is achieved in traits showing a high value of the mean (traits that match the brand). The brands would be linked by what defines them. These were the reasons why we selected charts comparing mean absolute differences in quadrants and mean values on the Likert scale to demonstrate the results.

Active, Responsible and Down to Earth interlink the brands of Škoda Auto and Ice Hockey World Championship most of all, while the pair consisting of Škoda Auto and Tour de France share only Active. The survey, however, does not determine whether the transfer of image occurs in one direction only, from the sport event to the sponsor's brand, or also in the opposite direction, from the sponsor's brand to the sport event. It can be assumed that Responsible, the trait that is more typical for the Škoda Auto brand, could transfer to the Ice Hockey World Championship due to long-term sponsorship. Another question suggests itself: can all congruent traits be assigned to the factor of long-term sponsorship? A situation may occur that certain personality 
traits are typical for both brands irrespective of sponsorship. In that case, it makes no difference whether the transfer of image and brand personality is considered to be the goal of sponsorship. Then, the congruence of image becomes a prerequisite and not a mere consequence of sponsorship. Providing it is a sufficiently strong player in the market, the international sport event can choose a sponsor whose traits are perceived by the public in a similar way and enter into a sponsorship agreement with such sponsor.

To investigate the factors of image transfer in sponsorship more thoroughly and precisely in the future, it would be advisable to focus on the context of environment and motivation of corporations to enter into sponsorship. Each international sport event is confronted with different natural, technical, and political challenges. These factors of the environment affect implementation of sponsorship. On the other hand, each company entering into sponsorship has its specific products and specific marketing communication of its brand. Sponsorship is a considerable investment and, as such, it is often designed to match specific needs of companies. For this reason, it is impossible to draw generally applicable conclusions from surveys examining sponsorship. In the future, research should focus on specific cases of sponsorship.

\section{CONCLUSION}

The research of congruence of the Škoda Auto, Ice Hockey World Championship and Tour de France brands showed that the duration of sponsorship may influence the brand personality. Partial congruence of certain personality traits was proved. Škoda Auto was identified as a responsible, active, and simple brand. Ice Hockey World Championship was identified as an active, responsible, and aggressive brand. Tour de France was identified as an active and partly also responsible brand. The identification of brand personalities thus indicated a potentially higher degree of congruence of personality traits between Škoda Auto and the Ice Hockey World Championship. Subsequent analysis of personality congruence was performed with the help of the absolute difference method developed by Gwinner and Eaton (1999). The values of the mean absolute difference prove that there is a higher degree of congruence between the brands of Škoda Auto and Ice Hockey World Championship than between Škoda Auto and Tour de France. Specifically, this applies to the following seven traits: Down to Earth, Responsible, Active, Bold, Ordinary, Romantic, and Sentimental. The remaining five traits showed a higher degree of congruence with Tour de France. After comparing the results of congruence with the results of personality identification, it was found that the Škoda Auto brand achieved congruence with the Ice Hockey World Championship in three traits that describe both brands: Active, Responsible, and Down to Earth. Only one congruent trait, Active, describes concurrently the Škoda Auto and Tour de France brands. 


\section{REFERENCES}

Aaker, J. L. (1997). Dimensions of brand personality. Journal of Marketing Research, 34(3), 347-357.

Ambroise, L., Ferrandi, J. M., Merunka, D., \& Vallette-Florence, P. (2005). How Well Does Brand Personality Predict Brand Choice? A Measurement Scale and Analysis Using Binary Regression Models. Asia Pacific Advances In Consumer Research, 6(1), 30-38.

Azoulay, A., \& Kapferer, J. N. (2003). Do brand personality scales really measure brand personality? Brand Management, 11(2), 143-155.

Chanavat, N., Martinent, G., \& Ferrand, A. (2010). Brand images causal relationships in a multiple sport event sponsorship context: Developing brand value through association with sponsees. European Sport Management Quarterly, 10(1), 49-74.

Čáslavová, E., \& Petráčková, J. (2011). The brand personality of large sport events. Kinesiology, 43(1), 91-106.

Čáslavová, E., \& Višněvský, A. (2016). Identification of Ice Hockey world Championship International sport Event through Brand personality. In: Conference proceeding World Academy of science, engineering and technology. Amsterodam The Netherlands Aug. 04-05. 18 (8), Part I, pp. 8-15.

Geuens, M., Weijters, B., \& De Wulf, K. (2009). A new measure of brand personality. International Journal of Research in Marketing, 26(2), 97-107.

Grohmann, B., Giese, J. L., \& Parkman, I. D. (2013). Using type font characteristics to communicate brand personality of new brands. Journal of Brand Management, 20(5), 389-403.

Gwinner, K. P., \& Eaton, J. (1999). Building Brand Image Through Event Sponsorship: The Role of Image Transfer. Joumal of Advertising, 28(4), 47-57.

Gwinner, K., \& Bennett, G. (2008). The Impact of Brand Cohesiveness and Sport Identification on Brand Fit in a Sponsorship Context. Journal of Sport Management, 22(4), 410-426.

IEG (2016). As Sponsorship Borders Fall, Spending Rises. Available online at: http://www .sponsorship.com (accessed 1 December 2016).

Keller, K. L. (2013). Strategic brand management: building, measuring and managing brand equity (4th ed.). Upper Saddle River: Pearson Prentice Hall.

Kim, Y. K., Shim, S. W., \& Dinnie, K. (2013). The Dimensions of Nation Brand Personality: A Study of Nine Countries. Corporate Reputation Review, 16(1), 34-47.

Lee, H. S., \& Cho, C. H. (2009). The matching effect of brand and sporting event personality: Sponsorship implications. Journal of Sport Management, 23(1), 41-64.

Lee, H. S., \& Cho, C. H. (2012). Sporting event personality: scale development and sponsorship implications. International Journal of Sports Marketing \& Sponsorship, 14(1), 51-68.

Lee, E. J. (2013). A Prototype of Multicomponent Brand Personality Structure: A Consumption Symbolism Approach. Psychology \& Marketing, 30(2), 173-186.

McDonald, C. (1991). Sponsorship and the image of the sponsor. European Journal of Marketing, 25(11), 31-38.

Macintosh, E., Nadeau, J., Seguin, B., O’Reilly, N., Bradish, C. L., \& Legg, D. (2012). The Role of Mega-sports Event Interest in Sponsorhip and Ambush Marketing Attitudes. Sport Marketing Quarterly, 21(1), 43-52.

Musante, M., \& Milne, G. R. (1999). Sport Sponsorship: Evaluating the Sport and Brand Image Match. International Journal of Sports Marketing and Sponsorship, 1(1), 32-47.

Neijens, P., Smit, E., \& Moorman, M. (2009). Taking up an event: brand image transfer during the FIFA World Cup. International Journal of Market Research, 51(5), 579-591.

Plumer, J. T. (1985). How personality makes a differences. Journal of Advertising Research, 24(6), 27-31.

Ross, S. D. (2008). Assessing the use of the brand personality scale in team sport. International Journal of Sport Management, 3(1/2), 23-38. 
Schade, M., Piehler, R., \& Burmann, C. (2014). Sport club brand personality scale (SCBPS): A new brand personality scale for sport clubs. Journal of Brand Management, 21(7-8), 650-663.

Stipp, H. (1998). The impact of Olympic sponsorship on corporate image. International Journal of Advertising, 17(1), 75-87.

Sung, Y., Choi, S. M., Ahn, H., \& Song, Y.-A. (2015). Dimensions of Luxury Brand Personality: Scale Development and Validation. Psychology \& Marketing, 32(1), 121-132.

Woisetschläger, D. M., Haselhoff, V., \& Backhaus, C. (2014). Fans' resistance to naming right sponsorships. European Journal of Marketing, 48(7/8), 1487-1510.

Woisetschläger, D. M., \& Manuel, M. (2012) Sponsorship congruence and brand image. A pre-post event analysis, European Journal of Marketing, 46(3/4), 509-523. 